\title{
A VELHICE VIVIDA E CONTADA PELAS PESSOAS DO ASSENTAMENTO COLÔNIA CONCEIÇÃO
}

\author{
Fábio Nunes Pereira \\ Rede Municipal de Educação de Nioaque - MS, Brasil \\ E-mail: fabiojoaoedite@hotmail.com \\ Orcid: https://orcid.org/0000-0001-8993-7091 \\ Alzira Salete Menegat \\ Universidade Federal da Grande Dourados, Brasil \\ E-mail: alziramenegat@ufgd.edu.br \\ ORCID: https://orcid.org/0000-0001-8777-7637
}

Data de recebimento: 06/06/2020

Data de aprovação: $25 / 07 / 2020$

DOI: https://doi.org/10.30612/frh.v22i40.13263

\begin{abstract}
Resumo: Neste artigo analisamos o sentido da velhice nos relatos das pessoas com 60 anos ou mais, assentadas na Colônia Conceição, assentamento rural localizado no município de Nioaque, em Mato Grosso do Sul. Aquele lugar conta com mais de 200 pessoas vivendo a fase da velhice, envolvidas com jornadas de trabalho nos lotes, construindo projetos para permanência, acalentadas pela sociabilidade que nutrem com a vizinhança. Nos arranjos cotidianos, o trabalho é o elo principal que as mantém na terra, ligado por um conjunto de elementos que se entrelaçam entre si, configurados no pertencimento à terra, nas relações de interação entre as pessoas, no fazer do processo produtivo e nos projetos futuros. Em 128 lotes existe a presença de pessoas na fase da velhice, administrando os lotes e evidenciando resistência ao viverem no assentamento.
\end{abstract}

Palavras-Chave: Assentamento, velhice, trabalho, projetos.

\section{THE OLD AGE LIVED AND TOLD BY THE PEOPLE OF THE SETTLEMENT COLONY CONCEIÇÃO}

\begin{abstract}
In this article we analyze the meaning of old age in the reports from people with 60 years or older, settled in Conceição Colony, a rural settlement located in the municipality of Nioaque, in Mato Grosso do Sul. That place has more than 200 people living the phase of old age, involved with working hours in the lots, building projects to stay in them, cherished by sociability with the neighborhood. In everyday arrangements, work is the main link that keeps them in the earth, connected by a set of elements that intertwine with each other, configured in belonging to the earth, in the relations of interaction between people, in the making of the productive process and in future projects. In 128 lots there is the presence of people in the phase of old age, doing the management the lots and showing resistance to live in the settlement.
\end{abstract}

Key-Words: Settlement, old age, work, projects. 


\section{LA VEJEZ VIVIÓ Y CONTADA POR LA GENTE DE LA COLONIA DE ASENTAMIENTOS CONCEIÁO}

Resumen: En este artículo analizamos el significado de la vejez en los informes de personas de 60 años o más, asentados en la Colonia Conceiáo, un asentamiento rural situado en el municipio de Nioaque, mato grosso do Sul. Ese lugar tiene más de 200 personas viviendo la fase de la vejez, involucradas con las horas de trabajo en los lotes, construyendo proyectos de permanencia, apreciados por la sociabilidad que nutren del vecindario. En los arreglos cotidianos, el trabajo es el principal eslabón que los mantiene en la tierra, unidos por un conjunto de elementos que se entrelazan, configurados en la pertenencia de la tierra, en las relaciones de interacción entre las personas, en la realización del proceso productivo y en futuros proyectos. En 128 lotes hay presencia de personas en la fase de vejez, gestionando los lotes y evidenciando resistencia cuando viven en el asentamiento.

Palabras Clave: Asentamiento, vejez, trabajo, proyectos.

\section{Introdução}

Neste artigo analisamos o sentido da velhice apresentado nos relatos das pessoas velhas do assentamento Colônia Conceição, localizado no município de Nioaque, em Mato Grosso do Sul. Naquele assentamento há número significativo de pessoas com 60 anos ou mais, vivendo a fase da velhice, combinando jornadas interpenetradas entre os trabalhos nos lotes e a sociabilidades com a vizinhança, construindo projetos para permanência, acalentados no futuro que já chegou. Apresentamos os arranjos que essas pessoas elaboram com base nos seus relatos, os quais expressam interações sociais, nutridas pelas lembranças vividas, comparadas com a vida sendo vivida no assentamento.

A memória dos assentados atua como fio condutor de lembranças da vida de cada um, e da vida em comunidade, num momento em que estão vivendo a fase da velhice, mas ainda atuantes no fazer produtivo dos lotes, lugar em que o cotidiano de trabalho exige esforço físico, embora suas forças diminuam.

Para entender a dimensão do assentamento os estudos de Heredia (1979) foram fundamentais, para pensar o sentido da morada da vida, elo que mantém as pessoas velhas nos lotes do assentamento e que compreende elementos que se entrelaçam, configurados no pertencimento à terra, nas relações com a vizinhança, no envolvimento com o fazer do processo de plantio e na dimensão da vida no lugar.

Outra categoria do estudo foi a da velhice, entendida como etapa da vida em que se chega aos 60 anos, fase que as pessoas em algum momento irão vivenciar, sendo um fenômeno 
natural biológico que tem na perda das capacidades físicas o ponto central. O estudo de Bosi (1994) com a memória de velhos se constituiu em outro aporte teórico para a pesquisa, recomendando as fontes orais para a compreensão da vivência das pessoas velhas.

Entre os 373 lotes que formam o assentamento Colônia, 128 deles são ocupados e administrados por pessoas de 60 anos ou mais, as quais produzem e estão mantendo e transformando o espaço. Isso demonstra resistência, visto que a luta pela terra, que os levou há 34 anos para aquele assentamento, está sendo por eles mantida, ao insistirem em viverem a velhice no assentamento.

Para a organização do texto, compomos três partes, sendo na primeira apresentadas considerações sobre a velhice, num diálogo com teorias que tratam do tema. Na segunda parte, apresentamos como a velhice é entendida pelas pessoas que fazem o movimento da vida no assentamento Colônia Conceição, na ênfase manifesta no trabalho. Na terceira parte, buscamos compreender a velhice para as mulheres assentadas.

\section{A velhice pelas trilhas das teorias}

Quando as pessoas chegam à velhice, uma série de questões vem à tona. Afinal o que é a velhice? Para Schneider e Irigaray (2008, p. 580), existem “[...] diferentes formas de definir e conceituar a velhice”. Uma delas versa sobre a idade cronológica, que atualmente vem sendo questionada, como apontam Rodrigues e Soares (2006, p. 4):

A idade cronológica é estabelecida independentemente da estrutura biológica e do grau de maturidade dos indivíduos, por exigências das leis que determinam direitos e deveres do cidadão e distribuem poder e privilégio. Devido ao caráter instrumental, as categorias de idade são construções culturais e sociais arbitrárias que atendem a interesses políticos de grupos sociais na luta pelo poder.

Abreu (2017, p. 26) destaca que há "um consenso que a fase da velhice se inicia por volta de 60 a 65 anos, com algumas variações, considerando o nível de desenvolvimento socioeconômico, o sexo, a cultura e outros fatores" do contexto do indivíduo.

No Brasil, existem parâmetros científicos e de legislação usados para qualificar quando a velhice chega para uma pessoa, e segundo o Estatuto do Idoso, sancionado pela Lei 10.741/2003, inicia-se aos 60 anos (BRASIL, 2003). O Estatuto visa a regular e garantir os direitos das pessoas com 60 anos ou mais, em substituição à legislação anterior (o Plano 
Nacional do Idoso, sancionado em 1994). No entanto, a velhice é constituída de um marco temporal que se aplica de forma diferenciada sobre os corpos.

Desse modo, se padronizarmos a fase da velhice somente com base na cronologia, atentando apenas para o tempo de vida das pessoas, sem considerar as particularidades sobre os vários envelhecimentos, colocaremos à margem a concepção política sobre velhice, elemento importante para compreendermos a totalidade social que a compõe. Rodrigues e Soares (2006, p. 7) nos falam de algumas classificações:

É do imaginário das representações que sairão os termos e as expressões classificatórias como velho e velhote, idoso e terceira idade. Tais termos e expressões são responsáveis pela construção de uma identidade estigmatizada, que acaba por excluir do processo social os indivíduos que se encontram com sessenta anos ou mais.

É preciso considerar que a sociedade é constituída de uma multiplicidade de grupos e de sujeitos sociais, que vivem lógicas diversas, as quais imprimem marcas do tempo também diversas sobre os corpos das pessoas, e por isso a existência de múltiplas velhices. Nesse bojo, um aspecto sobre a velhice parece único: a categorização social das pessoas consideradas velhas, que pode levar a estigmatização.

O envelhecimento, e, sobretudo, a velhice, não se processam de forma homogênea, linear, mas se revelam de múltiplas formas, com suas inconstâncias, sobretudo, carregada de preconceito social, como destacado por Schneider e Irigaray (2008, p. 588-589):

A existência de múltiplas palavras para nomear a velhice revela o quanto o processo de envelhecimento é complexo, negado evita ou mesmo temido. Evidencia claramente a existência de preconceitos, tanto por parte da pessoa idosa quanto da sociedade. As pessoas idosas e a sociedade em geral precisam se reeducar quanto à superação de ideias preconceituosas, pois se tornar velho é aceitar a velhice e ser orgulhoso dos muitos anos que conferem experiência, sabedoria e liberdade.

Nesses diálogos com os autores vemos que o envelhecimento precisa ser entendido em sua plenitude, alçando nessa discussão todos os seguimentos sociais, seja nas escolas, nos segmentos do mercado, nas políticas públicas que atentem para o amparo à velhice, trazendo esse debate para pauta do dia. Essa pauta deve constar desde a infância até a idade adulta, levando a população em geral a considerar essa etapa como parte do percurso da vida das pessoas e da dinâmica da sociedade. Com isso, criaríamos condições de superação do temor em relação a essa fase. Superaríamos também a ideia de descarte, presente na estigmatização social da velhice e que decorre dos referenciais da lógica capitalista, os quais enxergam os velhos 
como seres não mais produtores de riquezas, além de considerar como grupo que demanda de investimentos do Estado em políticas de atendimento à saúde.

O preconceito com a velhice nega o percurso de atuação das pessoas velhas e produz a ideia de fardo social, resultando num imaginário que vislumbra essa etapa da vida como algo ruim, acentuando estereótipos sobre pessoas velhas, bem como recusa discutir a presença da velhice como parte do percurso das pessoas em sociedade. É preciso humanizar as estruturas sociais, nas quais as pessoas se enxerguem como seres sociais, antes de serem produtoras de riquezas, reelaborando o imaginário social, visando à superação do medo da velhice. Medo fomentado pela lógica produtiva, que impõe utilidade contínua sobre corpos. No entanto, as etapas da vida das pessoas são distintas, vividas em conformidade com critérios inerentes a cada fase e com lógicas dos distintos grupos e espaços sociais.

Com esses referenciais procuramos entender a velhice na Colônia Conceição, dialogando com pessoas que se encontram vivendo a velhice, compreendendo o que é viver essa etapa da vida em assentamento de reforma agrária, lugar de trabalho pesado, e como promovem elos de pertencimento no contexto da comunidade que compõem.

\section{O trabalho como elo no viverem a velhice no Assentamento}

O assentamento Colônia Conceição foi criado no município de Nioaque, no dia 25 de junho de 1985, sob a Resolução de N. ${ }^{\circ}$ 060, pelo Instituto Nacional de Colonização e Reforma Agrária (INCRA). A área agrega 10.587 hectares, atendendo a 373 famílias. Sua instalação ocorreu num momento em que se iniciava no Brasil o I Plano Nacional de Reforma Agrária. A desapropriação da área da Colônia Conceição ocorreu após longas discussões e demandas encaminhadas nessa direção pelos movimentos sociais rurais, sendo mediada pela Comissão Pastoral da Terra (CPT), por meio de seus agentes, sobretudo, religiosos, como padres e freiras.

Passados 34 anos da instalação do assentamento, houve reconfiguração da área inicial, onde predomina a atividade pecuária, atividade que exige agilidade na lida com o gado. Nos 373 lotes da Colônia, em 230 deles existem pessoas residindo. No total dos 230 lotes com residências, em 128 deles existem velhos, e em 85 desses a administração é feita unicamente por eles. Nos outros 43 lotes existem velhos que moram com parentes mais jovens. Os demais, 102 lotes que somam os 230 lotes com pessoas neles residindo, são ocupados por aquelas com menos de 59 anos de idade. Os 143 lotes restantes, que somam o total dos 373 lotes, estão vazios da presença de pessoas residindo, sendo destinados para a criação de gado. 
Há, então, um percentual significativo de velhos na gestão das unidades, somando a maioria. No entanto, o número de pessoas na fase da velhice aumenta quando consideradas outras variáveis, dentre elas a existência nos lotes de casais de velhos, que, quando somados àqueles que residem nos pequenos lotes da Agrovila (lugar de lotes com formato urbano, onde ocorre pequeno comércio), chegam a 200 pessoas de 60 anos ou mais. Vejamos alguns números:

Quadro I: Mulheres e homens na fase da velhice nos lotes na colônia

\begin{tabular}{|l|l|}
\hline Velhos & Quantidades \\
\hline Mulheres & 91 \\
Casadas & $\downarrow$ \\
Viúvas & 68 \\
& $\downarrow$ \\
\hline Homens & 23 \\
\hline & 109 \\
Casados & $\downarrow$ \\
Viúvos & 95 \\
Separados ou solteiros & $\downarrow$ \\
\hline Total de velhos & 06 \\
\hline
\end{tabular}

Fonte: Dados da pesquisa de campo.

De acordo com o quadro, dos 200 velhos que vivem nos lotes da Colônia Conceição, há ligeira desproporção entre homens e mulheres. O que chama a atenção nesses dados é a quantidade de mulheres viúvas, a qual é bem superior ao número de homens. Isso ocorre, em parte, porque os homens que ficaram viúvos ao longo do tempo refizeram suas vidas com outras companheiras. Os viúvos se casam com mais frequência que as viúvas, como apontam Fernandes e Garcia (2010, p. 778):

No caso do homem idoso, geralmente, a experiência da viuvez transcorre entre a desvalia (helplessness) doméstica e o recurso aos saberes e ajudas de outras mulheres, geralmente do próprio círculo familiar. Com meios próprios de subsistência, a maioria recasa, sem grande demora, quase sempre com mulheres mais jovens do que a esposa anterior.

Inferimos que para a maioria dos homens velhos, residentes na Colônia, viver a viuvez sem contar com uma companheira se apresenta diferente das mulheres. Eles em sua maioria 
casam-se outra vez. Por outro lado, parte significativa das mulheres, que ficaram viúvas, não refaz a vida conjugal, o que ocorre por diversas razões, como expõem Fernandes e Garcia (2010, p. 782):

\begin{abstract}
Nesse processo de reconstrução de um novo sentido para suas vidas na velhice, as mulheres viúvas, em sua maioria, não incluem a busca de um novo parceiro, pois a vivencia de sua sexualidade e afetividade no casamento foi desprovida de prazer, centrada especialmente na reprodução e na submissão de sua corporalidade, como mulher casada e obediente. Essas memórias apagam seu interesse de estabelecer novas relações afetivas.
\end{abstract}

Às razões apresentadas pelos autores somam-se outras no assentamento Conceição, em razão de as mulheres optarem por ficarem sozinhas após a viuvez, ou com algum filho, como, por exemplo: a influência dos filhos para não se casarem novamente; a liberdade de viver em outra condição, em que possam ir e vir com maior independência; o desejo de cuidarem apenas delas, dentre outros motivos.

Historicamente as mulheres exercem o cuidado sobre os seus familiares, companheiro e filhos/as, muito mais que os homens, visto que lhe é ainda cobrada essa função, tão interiorizada pelas mulheres e por vezes até despercebida, pelo ato de sua naturalização social. Dessa forma, o fato de não constituírem uma nova família, no momento da viuvez, pode estar associado ao desejo de cuidarem apenas de si e isso é libertador, porque evidencia autonomia das mulheres, superando o quadro de dependência e dominação que podem ter vivido durante o casamento. Contraditoriamente, nem sempre no cenário social a opção pela vida feminina solitária é compreendida como autonomia, uma vez que, ainda, vigora a ideia equivocada de que as mulheres precisam ser amparadas.

No total das 200 pessoas velhas da Colônia Conceição, somam um número de 151 que se encontra com menos de 75 anos de idade e 49 acima dos 75 anos. Embora em ambos os grupos etários existam diversos fatores que interfiram ou se apresentem na saúde desses velhos, esses não estão atrapalhando o desempenho no trabalho, especialmente, no caso daqueles que se encontram no grupo abaixo dos 75 anos. É notável que esse grupo entre 60 a 75 anos possui saúde considerada entre ótima, boa e regular, conforme nos relataram os agentes de saúde. Ainda estão contribuindo com a economia local mediante o trabalho em seus lotes, além do que consomem com a aposentadoria. O bem-estar físico culmina com o trabalho, pois os velhos são habituados a realizarem alguma atividade relacionada ao lote. Desse modo, estão trabalhando e produzindo em plena velhice, como destaca o assentado: 
Eu faço todo o serviço do lote, eu paço veneno dos pastos, arrumo as acercas, roço. Eu ainda dou conta de cuidar do gado, até um tempinho desses fazia serviço pra fora, mas agora eu parei. Agora eu percebo que a gente trabalha mais não no ritmo que era antes, você faz as coisas mais devagar. Mais graças a Deus os serviços aqui eu faço todos, desde a cerca, a mangueira e cuidar do gado, minha saúde até agora está sendo dez. (Assentado na colônia, linha do Taquarussu, 71 anos de idade. Entrevista gravada no ano de 2019).

Nesse aspecto, embora aposentados, estão, de alguma forma sendo provedores, combinando momentos de trabalho com momentos de descanso, ou seja, o tempo do trabalho não pode ser deixado para traz pelo fato de se encontrarem vivendo a etapa da velhice. O sentido da vida está no movimento, o qual passa pelo trabalho no lote, mesmo que seja com menor frequência e intensidade. Trabalhar significa demonstrar para si que possuem saúde, mas medindo quanto podem e quais tarefas devem realizar no dia a dia.

Nos 128 lotes de posse dos velhos, em 125 deles a economia tem como base a pecuária de corte, uma atividade promotora da geração de renda na Colônia. Os trabalhos dos lotes não se restringem apenas à lida com o gado, mas envolve o fazer do entorno da casa e na própria casa. No entorno, é possível encontrar aves, como galináceos, usados como alternativa para suprirem a necessidade de proteína e para servir a carne das aves para as visitas que chegam da cidade.

A maioria dos velhos gosta da vida na Colônia Conceição e descumpre a indicação dos parentes e recusam convites para morarem na cidade, como aponta um assentado ao relatar a insistência da filha para que mude e ele disse: "Tenho medo de cidade". Assim, os velhos acionam seus mecanismos de resistência, como no exemplo do assentado de 81 anos, que usa o argumento para dizer não, ao desejo de alguns filhos, para que ele deixe o assentamento para morar na cidade.

Eu não vou, enquanto eu puder mexer aqui eu não vou não. Porque na cidade, todo mundo fala, tem um conforto, tem sim, mas se ele tiver o dinheiro, se ele não tiver se for ao hospital chega ao corredor e fica lá sentado. Eu digo por que aconteceu comigo quando eu fui pra lá. Se eu não tivesse um dinheiro aqui, eu era "pitoco", teria o braço amputado. Então, enquanto eu puder ficar por aqui, eu tenho o ovo, eu tenho a galinha, de vez em quando eu mato uma novilha, e eu vou aqui no córrego, pego um peixe. E lá na cidade tudo é no mercado. Então tem pessoas que falam: "eu vou pra cidade por causa da saúde", mas se fosse assim o médico não morria. (Assentado na Colônia, linha da Sede, 81 anos de idade. Entrevista gravada no ano de 2019).

Na fala do assentado, o fato de ele viver na Colônia significa que ele mesmo está a produzir seu próprio remédio, configurado no alimento que produz, no ovo, na carne de frango, 
de gado e no peixe. Isso tudo ele não teria com facilidade, caso optasse em viver nas cidades. Isso não significa que os velhos não precisem e/ou recusem a proteção dos parentes, eles querem viver em seus lotes, mesmo com alguma dificuldade. Nessa vivência, são imprescindíveis alguns mecanismos de proteção, que possam vir de parentes e vizinhos, como indica Carvalho (2010, p. 75): “Há um tipo de proteção - preciosa - que advém das redes de relações de proximidades geradas pela família e grupos/organizações comunitárias do microterritório. Não ter família e comunidade significa não ter proteção".

Continuar ativo, realizando algumas tarefas é uma forma de se sentir vivo, e enquanto há vida, planeja-se, realiza-se, vive-se a velhice. Acreditamos que os velhos, cada um à sua maneira, lançam mão de algum mecanismo para continuarem tocando as suas vidas. Um dos elos que os mantem no assentamento está no fato de poderem viver a velhice, rememorando trajetórias e chegando à avaliação de que o percurso trouxe frutos, configurados no que denominam de sossego. Nesse formato, a memória transcende fronteiras, barreiras do tempo e, sobretudo, aponta para a superação, mesmo que estejam vivendo a etapa das limitações físicas impostas pela idade.

O aporte entre velhos com companheiras/os permite que eles se ajudem, se articulem, enfim somem forças para serem capazes de continuarem firmes em seus propósitos, de viverem a calmaria do ambiente do assentamento. Com essa força concentrada, filhos e ou parentes se integram a esses velhos ao menos nos fins de semanas e feriados.

Aqui eu considero normal estar apenas eu e a mulher, porque o lote é pequeno, então não dá pra por mais pessoas. Então tem que ser só eu e ela mesmo, pra fazer o trabalho ainda estou conseguindo, dá pra ir tocando. Eu acho muito bom, ter a mulher aqui comigo, estamos indo bem, então tá muito bom, não temos atrapalho nenhum. Os filhos moram perto, sempre estão por aqui passeando. (Assentado na Colônia, linha da Jaguatirica, 62 anos de idade. Entrevista gravada no ano de 2019).

"Eu acho bom" viver somente o casal, pois assim "não tem atrapalho", no dizer do assentado, que vive com sua companheira, os quais estão desenvolvendo o trabalho do lote pelas suas próprias forças. Essa expressão indica que cumpriram com a criação da família e agora chegou a hora de desfrutarem de sossego. Ter os filhos por perto, passeando nos finais de semana, é condição que prezam, mas também gostam da vida calma que, na velhice, apenas o casal desfruta. A casa desses velhos é, em certa medida, um lugar de lazer para a família toda, recebendo aqueles que buscaram outros espaços. Esse campo se consolida como a casa de todos, 
de modo que sempre que possível algum familiar aparece para comer uma galinha caipira e ou fazer um churrasco, hábitos muito comuns na Colônia. Os visitantes passam alguns dias de confraternização, e depois seguem sua vida e os velhos retomam a rotina dos trabalhos do lote, independentes, autônomos, como parecem desejar.

Nos lotes onde um dos cônjuges faleceu, também ocorre os encontros familiares. Contudo, esses encontros não seguem mais a mesma intensidade de quando vivia o casal. Isso porque aquele que ficou se sente mais livre para se ausentar de tempos em tempos do lote, passando a combinar a vida entre diferentes espaços, que a condição do viver sozinho propicia. Desse modo, vive parte dos meses no lote e outra parte fora dele. Essa situação se faz mais presente quando da morte do homem, e a mulher mantém essa constância entre estar no assentamento e fora dele.

Contudo, naqueles lotes onde têm pessoas mais jovens, há um fôlego maior em relação a uma série de afazeres, possíveis com o apoio desses jovens que em certa medida poderão prestar apoio para seus pais e, também, para os vizinhos. Assim, fortalecem a rede de solidariedade entre assentados, através do trabalho sazonal, das empreitas e favores aos velhos, em suas solicitações em momento de precisão. As experiências de cada um, vividas em diferentes contextos sociais até chegarem ao assentamento, são ricas, como na narrativa do assentado de 71 anos de idade.

Eu tenho lembranças más, assim da pobreza, porque meus pais eram pobres, a gente passou uma vidinha muito feia, financeiramente ruim. Mas eu tenho lembranças boas de quando a gente era criança. Que tinha os pais tinha os avós, tinha os tios. Hoje eu tenho saudades disso aí, nenhum deles eu tenho mais, só alguns tios e eu tenho lembranças boas de colegas. (...) E tenho essas lembranças, dava prazer à gente se ajuntar, jogar futebol, a gente brincar, mesmo que eu não sou jogador, eu tenho essas lembranças assim, muito boa. Você tinha saúde, nunca tive em hospital, a única vez que fui, foi porque eu intoxiquei com veneno, fui tratar em São Paulo, mas graças a Deus eu tenho uma saúde boa. (Assentado na colônia, Linha do Mané, 71 anos de idade. Entrevista gravada no ano de 2019).

A velhice, na fala do assentado, compõe a somatória do viver um tempo longo. Nela, vão se somando acontecimentos que constituíram sua trajetória, trazidos pelas lembranças, da diversão, da sociabilidade familiar, da pobreza, formando elos dentre os múltiplos fios que compõem o arquivo da memória. Por meio desses elos, tece balanços do vivido, avaliando tempos remotos, numa interface com os tempos presentes, estabelecendo um vai e vem entre distintos tempos, e com isso vislumbra a velhice presente, manifesta no desaparecimento do 
vigor físico e na ausência dos familiares. Em outro depoimento, o relato da assentada aponta memórias de uma caminhada permeada pelas dificuldades, migrando de um lugar a outro, carregando as trouxas e os "filhos que Deus mandava".

Quando eu era criança, mocinha, eu trabalhava seis dias da semana mais meu pai, meus irmãos. Eu tinha sossego, tinha prazer na minha vida. Só que depois que eu casei com dezessete anos, eu foi pra roça novamente, e saí de lá, vim para esse Estado e só vivia com uma trocha nas costas e um filho nos braços. Era pra cima e pra baixo, e aí já perdi o sossego. Eu vim a ter sossego outra vez, depois que cheguei aqui na Colônia, porque aqui eu mando, porque é meu o lote. (Assentada na Colônia, linha da Sede, 75 anos de idade. Entrevista gravada no ano de 2019).

As lembranças se parecem com remédios, quando seus efeitos anestesiam as carências vividas, as dores e as perdas enfrentadas nos caminhos da vida. $\mathrm{O}$ anestésico funciona pelo efeito da cronologia, que no vai e vem dos tempos faz circular a precariedade. Traz à cena as conquistas, o que a assentada denomina do sossego alcançado, mesmo que a saudade de outras paragens da vida ainda se manifeste no arquivo da memória. Nesse balanço, emerge a saudade daqueles que se foram, do que se era, contrastando com a vida sendo vivida, sem a certeza do que se espera. Por isso, é corriqueiro ouvir das pessoas velhas a frase: "vou vivendo até que Deus quer", que parece indicar um cunho religioso, mas que retrata a incerteza diante das condições postas e no devir do amanhã, até mesmo porque o amanhã já chegou.

Uma das maiores preocupações dos velhos na Colônia versa sobre a sua condição física para desempenharem certas tarefas do dia a dia. Essa é também parte das preocupações de filhos e parentes, vivendo próximos ou não, pois esse elemento é central nas tomadas de decisões dos velhos. Por isso, ter saúde para os mais velhos é imprescindível, pois impacta positivamente em todos os seguimentos da vida, “[...] envelhecer bem significa estar satisfeito com a vida atual e ter expectativas positivas em relação ao futuro" (NERI, 1993, p. 11).

Portanto, o envelhecer bem se mostra numa linha tênue, na qual “[...] predomina o ponto de vista de que envelhecer satisfatoriamente depende do delicado equilíbrio entre as limitações e as potencialidades do indivíduo que lhe possibilitará lidar, em diferentes graus de eficácia, com as perdas inevitáveis do envelhecimento" (NERI, 1993, p. 13). Ou seja, embora em plena velhice e/ou vivendo a velhice, a capacidade de desempenhar tarefas, mesmo que seja em menor grau e intensidade, é visto como algo extremamente positivo para os velhos da Colônia Conceição. Ademais, eles não contam com a presença dos mais jovens em todos os momentos, sendo, portanto, fundamental terem minimamente condição física para bem viver 
nos assentamento. Vejamos como relata o assentado de 71 anos, sobre sua rotina dentro da Colônia:

Aqui já tem mais de 5 anos que eu faço caminhada todo dia, eu tenho prazer de levantar cedo e andar 4, ou 5 quilômetros. Depois vou dar uma olhada no gado, vou lá no meio das vacas, eu tenho prazer de olhar. Não tenho outra alegria, isso pra mim já é uma alegria de fazer a caminhada e ir olhar o gado, mexer com a cerca, olhar a cerca. E na cidade, o que e eu vou fazer na cidade? Lá eu fico dentro de quatro paredes, não tem pra onde sair, o vizinho do lado trabalha o outro do outro lado também trabalha o da frente também. (Assentado na colônia, linha do Mané, 71 anos de idade. Entrevista gravada no ano de 2019).

Para esse assentado, estar em movimento, poder cuidar do seu gado, significa ao mesmo tempo cuidar de si, estar de bem com a vida, mesmo trabalhando em uma atividade que é a pecuária de corte, na qual os animais são ágeis e apresentam riscos de acidentes, especialmente, para os velhos, com destreza diminuída. No entanto, a palavra "alegria", relatada por ele, demonstra prazer de viver e de contemplar o que conseguiu construir no lote do assentamento, estabelecendo um elo entre velhice e lugar. É no lote, e não na cidade, que ele consegue satisfação com o seu modo de vida, trabalhando, caminhando, contemplando o que fez e ainda faz, sobretudo, com a tranquilidade e sossego em residir na Colônia. Nesse movimento, o assentado mistura trabalho com lazer e o fato de poder caminhar e, ao mesmo tempo, cuidar do gado, apesar dos 71 anos, demonstra que o velho se sente bem para tanto.

O que interessa para os velhos da Colônia é poder continuar realizando trabalhos, seja em casa, no entorno dela e nas atividades de campo, ou seja, o trabalho como elementos para manterem-se ativos, capazes de tocarem seus lotes. "A 'idade funcional' é conceituada em termos da capacidade de adaptação do indivíduo ao ambiente" (NERI, 1993, p. 35).

As questões biológicas e funcionais que incidem na qualidade de vida dos velhos passam pela capacidade de se adaptarem, escolherem tarefas que ainda lhes permitem manterem-se ativos. Contudo, a aceitação da condição de velho pode ajudar nas escolhas e evitar trabalhos que prejudiquem a saúde. Nesse sentido, “[...] muita gente simplesmente aceita a velhice, com todas as suas desvantagens; deixam para suas dores e perdas, e se resignam a sofrer em silêncio. Outros sentem rancor, protestam e blasfemam contra ela" (SKINNER; VAUGHAN, 1985, p. 21-22).

A condição colocada pelos autores não é diferente na rotina dos assentados velhos, pois nem tudo que fazem deveria ser realizado por eles. Mas, cada um a seu modo teima em fazer algo que não deveria mais realizar. Outros preferem abdicar das tarefas, embora ainda 
gostem de realizá-las. Porém, não as realiza em nome de aproveitar um pouco da vida que lhes resta com algo mais prazeroso. Sobre o trabalho, o velho de 65 anos descreve:

Quando você passa dos 60, você já começa a sentir canseira. Logico está com saúde está tudo bem, mas não faz tudo aquilo que fazia não. Eu com os meus 30 anos era uma coisa, eu começava a trabalhar cedo e largava de noite. Eu lembro que trabalhei tanto aqui um dia que me deu ânsia de vomito de tanto trabalhar. Hoje não, hoje eu trabalho se for trabalhar eu trabalho o dia inteiro. Mas moderado, mas continuo, não paro. Mas sou mais igual aos 40, 50 não. Vamos pôr que dos $100 \%$, hoje estou $60 \%, 40 \%$ já foi. (Assentado na colônia, linha da Jaguatirica, 65 anos de idade. Entrevista gravada no ano de 2019).

$\mathrm{Na}$ fala do assentado, está a mudança na rotina de trabalho em virtude de contar com $60 \%$ da força que ele detinha, visto que o tempo levou os outros $40 \%$ e ele precisou se ajustar ao novo tempo, que já não é aquele da chegada à Colônia, quando tinha 30 e poucos anos. Atualmente sua jornada é de trabalho, mas com outra intensidade, ajustada de acordo com sua idade. A relação trabalho versos descanso é cultivada por esses assentados aposentados, que apesar de ainda trabalharem, o fazem de maneira menos intensa, mas assim continuam realizando alguma tarefa.

Os velhos, além de realizarem suas atividades necessárias para a manutenção dos lotes, planejam neles algumas melhorias para o futuro, como reforma de pastagem, construção ou reconstrução de corrais, manutenção e reconstrução de cercas, como também a ampliação e reforma das casas e entorno delas. O assentado de 71 anos descreve assim o seu sonho de melhoria para sua casa:

Aqui dentro do lote eu tenho vontade de construir mais um pedaço aqui na casa, porque a família vai crescendo mais. Quando vem tudo (parentes que moram fora) a casa fica pequena, então eu quero aumentar mais, e enquanto a vida eu vou trabalhando, movimentando pra não ficar parado. Não pode ficar parado de tudo, porque senão entreva tudo. (Assentado na colônia, linha do Mané, 71 anos de idade. Entrevista gravada no ano de 2019).

Notamos pelo depoimento do assentado, que ele manifesta a intenção de ampliar a casa, pensando no conforto dos parentes que os visitam com alguma regularidade. Contudo, ele também externa a preocupação de se manter ativo, em que o envelhecer, na opinião dele, pede constante movimento, evitando perder cada vez mais a mobilidade física. Outro assentado, com 65 anos, relata seus motivos para continuar sonhando em realizar outras melhorias na sua casa. Segundo ele: 
Todos nós queremos melhorar. O ser humano é assim. Eu também tenho que pensar isso. As vezes o cara quer melhorar uma casa, então melhora, pois a tendência é viver aqui. Você pensa em fazer melhoria, você não tem dúvida. Isso eu penso, hoje eu estou com 65 anos, mas daqui a 20 anos eu estou com 85 anos, uma idade considerável, mas ainda da para fazer alguma coisa. Eu penso também, tem os filhos, tem que melhorar alguma coisa, dentro de 5 anos você faz alguma coisa boa. Você tendo o recurso você faz coisa boa, deixa tudo pronto. É o que nós vamos fazer. (Assentado na colônia, linha da Jaguatirica, 65 anos de idade. Entrevista Gravada no ano de 2019).

$\mathrm{Na}$ fala do assentado, percebemos como ele vem planejando a velhice, buscando criar condições mais favoráveis para que possa chegar aos 80 anos vivendo na Colônia e com conforto. Para isso, ele atualmente elabora o que fazer enquanto conta com vigor físico e, assim, assegura meios para viver a velhice no lugar. A preocupação não está na beleza do corpo, mas na melhoria do lugar.

Diante dessa realidade, encontram-se os velhos buscando o atendimento à saúde, especialmente no posto de saúde do assentamento. Eles estão preocupados com os fatores de risco, como diabetes, pressão arterial, colesterol, enfim com todos os problemas de saúde que possuem ou que possam acometê-los, como analisaremos adiante. Sempre vigilantes, pois “"[...] o bem viver deve ser garimpado grão em grão. Mas aqueles que garimparem com afinco, extrairão do cascalho uma rica retribuição" (SKINNER; VAUGHAN, 1985, p. 34).

Para cuidar da saúde, os assentados frequentam as unidades de atendimento no assentamento e lá conseguem aferir a pressão arterial, o colesterol, a glicose, por exemplo. Embora tenham de reduzir a carga de trabalho, principalmente aqueles trabalhos pesados, parar de vez também não seria a solução, pois estarem ativos, para esses assentados velhos, significa manterem-se vivos, desempenhando alguma tarefa.

No entanto, tanto as tarefas domésticas, quando as atividades de campo exigem certo grau de esforço. Portanto, os seus malefícios para a saúde também são inevitáveis, quando de idade avançada, podem incidir em lesões físicas, capazes de causar problemas nas pessoas com idade avançada. Se isso ocorrer, eles terão mais dificuldades para continuarem com o seu modo de vida, ou seja, residindo no lote. Então, atentar para o que podem ainda realizar é o mesmo que garantir sua continuação e manutenção do seu modo de vida, minimizando os desgastes físicos e podendo continuar ativos, desenvolvendo atividades menos desgastantes, como aponta um assentado.

Minha saúde é boa, só tenho problemas de coluna, e eu tenho que viver, como 4 médicos diz pra mim: "o senhor tem que viver com a dor de coluna, viver com a dor, porque isso aí não vai sarar". Então o que eu sinto mais é a coluna. 
$\mathrm{Na}$ velhice é a minha coluna que não dá mais pra fazer o que a gente tem vontade de fazer. Você tenta, mas machuca muito. (Assentado na colônia, linha da Sede, 81 anos de idade. Entrevista gravada no ano de 2019).

Para continuarem ativos durante a velhice, certos cuidados com a saúde são imprescindíveis. Desse modo, as pessoas velhas são o grupo populacional mais frequente na unidade de saúde local. Na maioria dos casos de atendimento à saúde, a população de velhos da Colônia destaca que conseguem ter atendimentos no posto de saúde local. Segundo eles, sempre são bem atendidos pelo médico e suas queixas são ouvidas e encaminhadas. Associado ao atendimento e cuidados com a saúde, proteção social, através da previdência social, é considerada pelos velhos da Colônia Conceição como fundamental na sua segurança financeira, pois é essa renda que garante a maioria dos produtos necessários para a subsistência. Ainda mais, o dinheiro da previdência lhes permite acessarem uma gama de possibilidades, proporcionadas por esse valor monetário, como aponta um assentado:

A aposentadoria é uma coisa boa, estamos vivendo com ela. A aposentadoria ajuda muito aqui, porque você sabe que todo mês tem aquele dinheiro pra fazer compra, pra pagar. Todo mês você sabe que esse dinheiro não vai faltar. Só se o governo quiser cortar, mas se ele fazer isso nós vamos pra cima e todo mundo faz manifestação, porque não pode né? Mas ajuda muito essa aposentadoria é uma maravilha. (Assentado na colônia, linha da Jaguatirica, 65 anos de idade. Entrevista gravada no ano de 2019).

$\mathrm{Na}$ fala do assentado, aparece o quanto a aposentadoria cumpre o papel de amparar esses velhos. Esse dinheiro é a principal âncora econômica para ter certa tranquilidade no dia a dia, ou seja, mesmo havendo outras fontes de receita, tais como a comercialização do gado, de leite e outros produtos, o que lhes permite continuarem com certa segurança econômica é a aposentadoria. As instabilidades climáticas podem oscilar a colheita e o ganho com a comercialização dos produtos, e por isso enxergam na receita gerada com a aposentadoria, a seguridade financeira, como diz uma assentada: "A aposentadoria é uma grande vantagem, porque com a aposentadoria a gente já não pensa de vender uma vaca, o dinheiro já tem, chega lá passa o cartão, faz a compra, é uma grande vantagem pra nós" (Assentado na Colônia, linha da Sede, 81 anos de idade. Entrevista gravada no ano de 2019).

Esses velhos contam cada qual com o equivalente ao valor de um salário mínimo (decorrente do benefício da aposentadoria). No caso de casal, a renda que conseguem é de dois salários mínimos, concedido pela previdência social, visto que segundo as regras atuais, existem as garantias do recebimento do benefício social para ambos os cônjuges. Em caso de falecimento de um deles, o outro passa a receber a aposentadoria daquele que faleceu, ficando, 
desse modo, assegurada a renda da família. Receber o benefício do cônjuge falecido é fundamental no momento em que vivem, pois se trata de uma fase que precisam dispor de recursos para compra de medicamentos e com isso manter a qualidade de vida. Se por um lado eles sentem certa segurança em terem esse dinheiro para o que necessitam, por outro lado, estar aposentado significa envelhecer e cada dia mais.

$\mathrm{Na}$ Colônia, os assentados estão contabilizando os rendimentos, entre aqueles decorrentes da aposentadoria, com aqueles do trabalho em seus lotes. O dinheiro das aposentadorias é usado para comprar alimento para os membros da família, como também ração e minerais para o gado e, ainda, pagar parcelas de algum produto adquirido na cidade, bem como contas de energia elétrica, dentre outros. Somado a esse rendimento criam o gado, outra fonte de renda a contar e que assegura qualidade de vida.

Nesse sentido, o trabalho para a pessoa velha da Colônia Conceição figura como estar apto, ser capaz de tocar a vida sozinha. O trabalho é o elo com tudo que são e com o que realizaram de atividades até aqui. E mais, estar em atividade os deixa em condição de independência para com os parentes. A decisão em pararem é uma condição que se acentua aos poucos, havendo, primeiro, uma espécie de escala das atividades que menos agradam, delegando-as a outros, sobretudo, aquelas mais penosas, como mostra o assentado de 71 anos:

Eu gosto de trabalhar, por exemplo, o que eu mais gosto, é pesado, que é fazer cerca. O roçar, carpir, eu não aguento muito não, uma hora é muito e eu já não aguento. Então, eu já penso em pagar alguém para roçar, mas no caso da cerca eu já gosto de fazer e tem que andar que se movimentar. (Assentado na colônia, linha do Mané, 71 anos de idade. Entrevista gravada no ano de 2019).

Para os velhos da Colônia, o que se observa é a tentativa de manterem seus lotes produtivos, além de fazerem adaptações em suas casas para torná-las mais acessíveis, assim como empreender esforços para melhorar a produção e contenção de seus rebanhos de gado. Por esse motivo, acreditamos que estão sempre preocupados com o futuro, no sentido de empreenderem cada vez mais. Dessa forma, ao planejarem projetos futuros, se mostrarem ativos na manutenção dos lotes, mesmo contratando força de trabalho para atividades mais pesadas, bem como reorganizando jornadas ao incluir horas de lazer nas jornadas, com pequenas viagens e/ou visitação na vizinhança, estão mantendo a si próprios, produzindo qualidade de vida na fase da velhice.

Um dos elementos que garante autonomia aos velhos da Colônia Conceição é o da presença de veículos em 89 das casas. A locomoção é fator agregador da qualidade de vida 
desses velhos, pois uma série de possibilidades se abre quando podem dirigir seus próprios veículos e ir e vir por maiores distâncias e sem dispenderem grande esforço físico.

Eu vou com o carro para Aquidauana, Nioaque, Jardim, Sidrolândia, só não vou pra Campo Grande, por causa do movimento e eu não tenho prática. Então eu vou até Sidrolândia, de lá quem leva o carro é meu genro. Lá o trânsito é mais pesado, então a gente tem mais um pouco de medo, não está acostumado com o trânsito. Se eu não tivesse um carro, seria mais difícil, eu teria que pagar um carro até o asfalto, teria que pegar um ônibus. (Assentado na colônia, linha da Jaguatirica, 62 anos de idade. Entrevista gravada no ano de 2019).

Possuir um automóvel viabiliza facilidades para irem às casas de vizinhos e parentes para passear, fazer compras na cidade, irem aos médicos sozinhos, assim como, o acesso a entretenimento e a lazer no âmbito da Colônia Conceição e fora dela, em lugares turísticos, tais como Bonito e Parque da Bodoquena. No caso dos velhos que não possuem veículo próprio, esses precisam contar com a carona, o frete, ou se locomoverem a pé. Em maiores distâncias podem acessar o transporte de ônibus, que trafega pela BR 419, em frete ao assentamento. Porém isso seria possível para aqueles que moram próximo ao asfalto, pois aqueles que residem mais distantes da referida BR precisam de caronas ou fretes, tanto para acessarem o asfalto, quanto para irem a lugares mais distantes.

Outro aspecto a destacar na vida dos velhos da Colônia Conceição é a possibilidade propiciada pela comunicação que mantem com a vizinhança ou mesmo os noticiários televisivos, acessíveis na Colônia, associados ao entretenimento ajudam a população do campo a sentirem-se mais próximas umas das outras. Embora a telefonia nem sempre esteja à disposição, devido às oscilações na transmissão do sinal, que chega fraco dentro da Colônia, conseguem fazer ligações e manter um canal permanente com os moradores e com os parentes que não vivem no assentamento. Esse é um fato importante, sobretudo, para os velhos, pois podem dialogar com vizinhos, combinarem viagens, receberem notícias dos parentes.

Desse modo, não vivem o isolamento nem se faz necessário percorrerem distâncias para se comunicarem, criando meios favoráveis nesse mundo moderno, como aponta Baumam (1999, p. 21): "Dentre todos os fatores técnicos da mobilidade, um papel particularmente importante foi desempenhado pelo transporte da informação - o tipo de comunicação que não envolve o movimento de corpos físicos ou só o faz secundariamente e marginalmente".

O telefone para os velhos é um canal de comunicação imprescindível, pois em momentos de necessidade, quando, por exemplo, tem algum animal doente, precisando de cuidados, o socorro chega, sem a necessidade de se deslocarem até a casa mais próxima para 
pedir ajuda. Isso também acontece com os cuidados com a própria saúde, que, em momentos de enfermidade, os assentados velhos conseguem rapidamente socorro. Atualmente, ter um telefone à mão se tornou coisa de primeira necessidade, seja para atender a questões de emergências que podem ocorrer, seja para viabilizar o contato com filhos e vizinhos diariamente, encurtando distâncias e produzindo certa sensação de segurança.

Quando um desses velhos se nega a comprar um telefone, de alguma forma é convencido pelos parentes e vizinhos a fazê-lo, pois não se pode ficar sem um canal de diálogo em plena velhice. Com a entrada do telefone, abrem-se as portas para outros meios de comunicação, além das ligações. Nesse sentido, surge à internet via rádio e satélite, e com isso as redes sociais proporcionam a ampliação da rede de diálogo, já que viabiliza as interações em um nível mais amplo. Ou seja, além das ligações e mensagens de texto, também podem utilizar o sistema de vídeos, associando o diálogo à presença on-line, encurtando distâncias, mesmo que a ausência ainda seja elemento presente.

Aqui o telefone não funciona todo dia, então a gente usa a internet para tá passando uma mensagem, pra falar com os filhos, ligar pra eles pelo WHATSAPP. Então melhorou bem graças a Deus, depois que nós colocamos a internet, tem hora que ela ajuda muito a gente, porque com ela você tem o que fazer até. A gente usa internet para comunicar com os filhos e com os vizinhos também, que às vezes eu tenho vontade de falar com alguém, mas a pessoa está lá na outra linha. Então eu passo uma mensagem de WHATSAPP. (Assentada na colônia, linha da Ilza, 69 anos de idade. Entrevista gravada no ano de 2019).

Frente à experimentação das redes sociais pelos velhos, seja em suas casas, seja nas casas de vizinhos, eles estão se familiarizado com as novidades tecnológicas e se acostumando e até desejando consumir mais esse serviço, fruto da sociedade moderna. Porém, na realidade que vivem, passa a ser um elemento fundamental, diminuindo o isolamento e servindo de auxiliar para momentos de necessidades.

\section{As mulheres assentadas e a velhice}

Delegar a outros as atividades mais prejudiciais à saúde não acontece com as mulheres que estão na fase da velhice no assentamento Colônia Conceição, visto que as elas continuam realizando as tarefas de uma vida toda, especialmente as domésticas. Mesmo vivenciando agruras causadas por problemas de saúde, sobretudo, nas articulações, as mulheres precisam desempenhar as atividades de sempre. Continuam lavando, passando, cozinhando, limpando. 
Todas essas tarefas são pesadas para as velhas, mas elas as desempenham diariamente, mesmo não tendo mais as condições físicas para tanto.

Então, podemos afirmar que as mulheres velhas não têm o poder de escolha sobre o que fazer ou não fazer. Elas se sujeitam a desempenharem o papel de donas de casa, fruto da construção social patriarcal, que parece se estender a todas as etapas da vida das mulheres. Além disso, “[...] as atividades da casa, por estarem ligadas ao consumo, não são consideradas como trabalho e correspondem à esfera de domínio feminino". O campo de ação da mulher é a casa e, por consequência, considera-se que esta não trabalha (HEREDIA, 1979, p. 80).

Nesse sentido, os homens velhos ainda gozam de uma situação de privilégio em detrimento das mulheres velhas, pois eles têm a opção de escolher o que fazer ou não diante da condição de velho. Já as mulheres continuam com a tarefa árdua de cuidarem da casa, mesmo se não tiverem saúde física para tal, como nos mostra uma assentada: "Eu lido com os desconfortos da saúde numa boa, eu costuro, gosto de uma roupa ajeitadinha, o dinheiro que eu tenho é para eu comprar meus negócios" (Assentada na colônia, linha do Mané, 73 Anos de idade. Entrevista gravada no ano de 2019).

Verificamos no relato da assentada um contentamento com o que ela faz, como se as dores fossem parte do fazer cotidiano a ela "destinado", e para isso, visando suaviza-lo, precisa "lidar numa boa". Nesse sentido, destacamos o fato de a sociedade, organizada sob a lógica do patriarcado, teimar em naturalizar funções específicas, principalmente, aquelas reservadas aos cuidados com a casa, que parecem penalizar as mulheres, o que é reflexo da cultura machista e, sobretudo, da não superação das desigualdades de gênero ainda presentes nas sociedades atuais.

Desse modo, as mulheres velhas na Colônia cerceiam parte dos cuidados com a saúde para realizarem trabalhos que não deveriam desempenhar, mas o fazem em nome de tudo que é delegado socialmente à mulher. Aceitam a sua condição de mulher dona do lar, mesmo não tendo condição física para tal.

Aqui você tem de tudo, água, luz. Eu como não posso andar muito, eu pego um cabo de vassoura, pra ir até ali nos meninos, para fazer uma caminhadinha. Com esse negócio do tratamento eu estou gastando 800 reais de remédio, só que não tenho nenhuma dor de cabeça. Esses dias fiquei gripada, mas não fiquei na cama. (Assentada na colônia, linha do Mané, 73 anos de idade. Entrevista gravada no ano de 2019).

De acordo com o relato da senhora de 73 anos, mesmo que não possa fazer muita coisa, ela procura manter-se ativa. Cabe destacar que as mulheres contam com a aposentadoria e, 
ainda assim, continuam a realizar os trabalhos que vinham desempenhando ao longo da vida, o que remete ao estudo de Menegat (2008), quando aponta para as diferenças sociais do trabalho doméstico, nem sempre compreendido na dimensão de trabalho, mas de serviço. Em se tratando do espaço doméstico, no imaginário social, predomina a ideia de que nele ocorre o serviço, com sentido de leveza, e por isso desempenhado por mulheres, também vistas como sexo frágil, atributo da desigualdade de gênero, que é histórica, ainda mantida na sociedade dos dias atuais.

Na velhice, as velhas, além de desempenharem as atividades domésticas, muitas vezes precisam participar das tarefas do lote, haja vista que falta mão de obra familiar. "Se a mulher participa das decisões, isso significa também que ela participa tanto das tarefas domésticas como das tarefas produtivas. Sua jornada de trabalho caracteriza-se pela junção dessas atividades" (SANTOS, 1978, p. 32). Desse modo, "embora se prefira que as mulheres não executem tarefas pesadas, como lavrar a terra ou colocar postes, quando os braços masculinos não são suficientes abandona-se esse padrão de divisão sexual do trabalho e a mulher trabalha" (SANTOS, 1978, p. 32).

O papel da mulher velha na Colônia é considerado imprescindível para a manutenção dos arranjos familiares, pois elas são aquelas que dão conta do que é necessário para a manutenção da família. Diante disso, é válido dizer que elas são o cerne da manutenção da unidade familiar. No que tange à velhice, as construções sociais negam à mulher uma condição de paridade frente aos homens, o que parece serem elas mais enrudecidas, embora saibamos que a sociedade caminha para algumas mudanças nesse sentido.

Então, quaisquer que sejam as rupturas possíveis diante dos papéis socialmente construídos para ambos os sexos esbarram-se nas supostas obrigações dentro do lote, entendidas como tarefa de homem e de mulher. Como aponta a senhora de 70 anos: "O marido fala que não consegue fazer as coisas de casa, que isso não é serviço de homem, mas consegue, é só querer fazer que consegue" (Assentada na colônia, linha do Taquarussu, 70 anos de idade. Entrevista gravada no ano de 2019). Para essa assentada, mesmo que ela esteja doente, não recebe a ajuda do marido em casa, e, conforme ela diz, é mais fácil ocorrer o contrário, ela ir ajudar o marido nos afazeres do lote.

Entendemos que as mulheres quando jovens casam-se e continuam a vida de cuidados com a casa, sobretudo, como provedoras dos alimentos consumidos pela família e realizadoras de todas as tarefas relacionadas ao espaço doméstico, como relata uma senhora de 68 anos: 
Eu sempre fiquei em casa, cuidando de tudo. O marido saía muito para fazer comércio. Então eu tirava leite, cuidava da casa e dos filhos. Quando os meninos cresceram eu parei de tirar o leite. Mas depois que eles cresceram, foram embora e eu voltei a tirar o leite. Acordo às cinco horas da manhã, tiro o leite, e venho pra dentro de casa, faço café, limpo a cozinha e vou prepara o almoço. Eu só sento pra descansar meio dia, após o almoço. (Assentada na Colônia, linha do Mané, 68 anos de idade. Entrevista gravada no ano de 2019).

Embora em plena velhice, elas se veem nos afazeres do lar, ainda como as provedoras. Isso ocorre mesmo que seus corpos deem sinais do quanto estão necessitando de recomposição de jornadas. Elas continuam se dedicando, como esforço último para não sucumbirem diante da debilidade por estarem velhas. Ainda mais:

[...] o corpo e a velhice dessas mulheres, diferentemente da experiência masculina, trazem marcas negativas imprimidas pelas suas condições de vida e de gênero, como mulher pobre e excluídas do poder, tanto no espaço público quanto no espaço privado do lar, na vivencia da maternidade e, sobretudo, nas relações conjugais (FERNANDES; GARCIA, 2010, p. 885).

Portanto, o peso da idade incide sobre as mulheres, provocada pelo que aponta as autoras, mas é agravada pela labuta empreendida no contexto do rural, dos papéis incumbidos a elas. Ao longo de suas vidas compuseram parte da força de trabalho no roçado, quando a família necessitava de todos os membros da unidade, momento em que cumpriram a dupla jornada. Por essas e outras razões entendemos que as mulheres velhas sentem ainda mais o peso em se manterem ativas em plena velhice, embora sintam nos corpos o peso da idade, manifesto nas dores que as acometem diante da velhice.

Eu sinto o cansaço à noite, quando eu tomo o remédio para a pressão, por isso que eu vou dormir tarde da noite. Dormir muito tarde, porque quando eu durmo, faço só dois sonos à noite. Ai eu levanto saldável, graças a Deus, para fazer minhas obrigações. Eu não sei da minha vida adiante, porque o cansaço vai chegar, dores nas pernas vai chegar, e eu sinto dores na coluna e artrose. Eu tomo remédio de oito em oito horas, eu tomo comprimidos, por conta dos meus problemas no braço, mas pra mim a vida é saudável. (Assentada na colônia, linha da sede, 75 anos de idade. Entrevista gravada no ano de 2019).

De acordo com esse depoimento, notamos a vulnerabilidade das mulheres velhas na Colônia Conceição. Para dormir profundamente, é preciso dormir tarde, quando chega à exaustão e assim não sentirá o peso do corpo ao repousar. Fará um "sono só", e assim não sentirá as dores pelo corpo. Novamente a dor naturalizada, aparecendo como parte da vida das mulheres e pelo fato que está envelhecendo, como a um ônus para o bônus de quem vive por 
muitos anos. Com isso neutralizam o sentimento da dor, colocando-a como parte da jornada e de dividendo por poderem viver o envelhecer.

Então, o dinamismo das mulheres vivendo a velhice está atrelado a uma série de atividades que as mantêm em movimentos, ou seja, jornada cheia, sentindo-se ativas e com muitos projetos, mesmo quando as doenças se manifestam como no relato de uma assentada que aponta para as mudanças corporais e para a necessidade de criar projetos voltados para si, para seu corpo.

Agora na velhice, eu sou mais igual eu era, porque as vezes a gente tem vontade de fazer alguma coisa, igual a minha hortinha ali, tudo eu que fiz, quando eu tinha um pouquinho de saúde e podia mexer, com pó, com pau. Quando eu tinha um arranhãozinho, eu vinha aqui passava um álcool e sarava. Hoje, a minha pele está muito fina e machuca em qualquer coisa que encosto. (Assentada na colônia, linha da sede, 75 anos de idade. Entrevista gravada no ano de 2019).

As mulheres até recebem aporte familiar nos trabalhos, contudo não é suficiente para as libertarem da carga dos trabalhos domésticos que ainda recai sobre elas. Infelizmente, embora os tempos tenham mudado, nos possibilitando enxergar que algumas arestas foram reparadas no sentido da igualdade de gênero, ainda existe um enorme caminho a percorrer, como aponta Pereira (2015, p. 50):

Os direitos aumentaram, mas a consciência social nem tanto, as mulheres conquistaram o espaço público em diferentes profissões, mas muitas continuam como as únicas responsáveis pelo espaço privado e pelo trabalho doméstico. E a rotina transformou se em um crescente acúmulo de trabalho, devido à constância da divisão sexual do trabalho doméstico em muitas famílias, que não se transformou em meio às mudanças as mudanças e ao avanço da autonomia das mulheres.

Pereira ainda nos diz que as " [...] mulheres passaram a dividir as despesas da casa com o marido e/ou demais integrantes da unidade familiar, mas as tarefas domésticas continuaram sob sua responsabilidade" (PEREIRA, 2015, p. 69). Então, apesar de estarem velhas, as mulheres assentadas na Colônia Conceição sempre estão de prontidão para continuarem com o seu papel de provedoras de seus lares. Por isso, é comum encontrar esposos e parentes mais jovens descansando às sobras das árvores, enquanto a velha senhora se dedica aos afazeres domésticos.

No entanto, é preciso reconhecer as resistências que as mulheres criam, visto que não são todas que vivem essa situação, existindo aquelas que vivenciam jornadas diferenciadas. Há, 
ainda, aquelas que ao ficarem viúvas passaram a cuidar apenas de si, numa autonomia feminina, como apontamos anteriormente. Além disso, é possível encontrar emancipação feminina com o benefício da aposentadoria no que se refere à gestão dos recursos advindos desse benefício, sendo elas autônomas em quê e no quê gastar o seu dinheiro. Certamente existe a negociação quando se trata de um casal de velhos, sobre o quê cada um emprega o dinheiro, ou seja, enquanto um paga a conta da energia elétrica, o outro compra o milho para o trato com a criação; se um compra o sal para o gado, o outro paga as parcelas de algum objeto comprado para a casa.

Comumente, também se encontram velhos que dividem todas as contas em partes iguais. Do mesmo modo, alguns velhos assumem as contas com o mercado, enquanto o outro cuida da saúde especialmente se existe a necessidade de compra de medicamentos ou de atendimento médico fora do assentamento. Em suma, são vários os arranjos possíveis, mas nesse quesito as mulheres se sentem emancipadas economicamente ao ter elas acesso ao dinheiro de suas aposentadorias e negociam com seus companheiros o que cada um deverá assumir.

Para as mulheres que em outros tempos não contavam com nenhum ganho, visto que, geralmente, eram os companheiros que negociavam os produtos e elas apenas assistiam às negociações, atualmente, o fato de elas terem seu próprio rendimento por meio da aposentadoria, e irem elas mesmas até o banco e lá receberem o valor do beneficio, que é repassado de forma pessoal, promove visibilidade e autonomia no seu uso.

O beneficio da aposentadoria é emancipatório para as mulheres, talvez o lado bom da velhice. Mesmo que tenham de negociar com o companheiro o que cada um deve pagar para a manutenção da unidade produtiva, é notório o poder de compra das mulheres. Com isso refazem inclusive jornadas, como aponta outra entrevistada, ao evidenciar que mesmo diante das limitações, está incluindo em seu cotidiano nova atividade, como ir à academia, no dizer da senhora de 75 anos:

Pra mim é uma beleza, "eu até me emociono", porque tem muita gente nova que não faz o que eu faço. Eu tenho vontade de fazer as coisas mais eu não posso, porque eu peguei um problema na pele. Diz o médico que a minha pele é muito sensível de mais. Esses machucados aqui é tudo onde eu toco, vai ficando essas marcas aqui. Mas olha só, hoje eu já molhei as minhas plantas, tomei um banho, troquei de roupa, arrumei a cozinha, já fiz comida para os cachorros. A minha vida tá assim. A tarde ainda vou na academia. Pra mim isso aí é uma beleza né? Eu peço a Deus, quando Deus quiser me carregar, carregar eu assim andando. (Assentada na colônia, linha da sede, 75 anos de idade. Entrevista gravada no ano de 2019). 
De acordo com o relato, é fato que a velhice se constata, com tudo que representa estar vivo para a pessoa velha. A mobilidade, o trabalho são motivos de alegria, por serem indicativos de saúde e disposição nessa etapa da vida, entrando em sua jornada exercícios físicos, que pareciam disponíveis apenas para as pessoas do meio urbano. E mais, a ênfase a emancipação de fazer o que ela deseja, a começar pela iniciativa de cuidar de si, o que remete a emancipação da mulher, pelo fato de fazer o que gosta de fazer e de se enxergar, na atenção que demanda ao corpo, uma "beleza", como ela diz. Ir à academia, cuidar de si é uma beleza. Molhar plantas, cuidar dos animais, de suas vestimentas, é parte da jornada dessa mulher, que mesmo diante de problemas com sua saúde, encontra meios para o bem viver. Com isso, pelo seu dizer, constrói vida e a morte irá carrega-la andando. Essa expressão contém dois sentidos, o da valorização do trabalho, que mesmo na velhice ainda está ativa, e aquele de criar meios para viver melhor, com atenção ao corpo, preocupando-se com seu bem viver.

O viver a velhice no assentamento Colônia Conceição para homens e mulheres, parece se constituir numa etapa da vida onde avaliam as muitas conquistas decorrentes da instalação do assentamento. Por isso acreditamos que os assentamentos no contexto do município de Nioaque, lugar que conta com um total de oito assentamentos (e mesmo no Brasil), não podem ser vistos apenas pelo viés do sucesso e insucesso econômico em termos da quantidade de produção neles obtida, mas é preciso contabilizar outros elementos, dentre eles o viver com dignidade, usufruindo do sossego na etapa da velhice, como recompensa pela luta empreendida.

\section{Considerações Finais}

Nos lotes do assentamento Colônia Conceição, encontramos maior parte dos assentados/as, pertencentes ao grupo de pessoas de 60 anos ou mais, vivendo a fase da velhice e, mesmo nessa etapa da vida, ainda atuantes no fazer produtivo dos lotes, num cotidiano de trabalho exige esforço físico. Deparamo-nos com pessoas velhas, mas ativas, cheias de planos, criando estratégias para a permanência em área de assentamento, ainda que com limitações impostas pela faixa etária em que se encontram.

Viver a velhice nos lotes do assentamento Colônia Conceição demonstra a morada da vida, onde há 34 anos essas pessoas estão construindo o sossego desejado, num misto de trabalho, descanso e resistência. As falas que apresentamos nos auxiliaram a entender que a velhice para as pessoas da Colônia figura como direito: direito à vida, direito ao modo como 
desejam viver e, especialmente, direito de viver por um longo tempo e em lotes de assentamento.

Além disso, o assentamento foi sendo constituído como lugar de outros direitos: da produção de alimentos, com olhar sobre o meio ambiente; da manutenção de referenciais culturais nutridos por determinados grupos sociais; da produção conforme as próprias necessidades das comunidades, mesmo nutrindo certo viés de mercado; e, especialmente, no direito à vida e do viver a velhice com sossego merecido, como uma recompensa pela labuta empreendida na trajetória das muitas andanças, até a chegada à morada da vida, no assentamento Colônia Conceição.

\section{Referências}

ABREU. Maria Celei de. Velhice: uma nova paisagem. São Paulo: Editora Agora. 2017.

BOSI, Ecléa. Memória e sociedade: lembranças dos velhos. 19a . Ed. São Paulo: Editora. Companhia das Letras, 1994.

BRASIL, Ministério da Saúde. Estatuto do Idoso. $1^{\text {a }}$ Ed, $2^{\text {a }}$ reimpr. - Brasília: Ministério da Saúde, 2003.

CALDAS, Célia Pereira; VERAS, Renato Peixoto. O lugar do Idoso na Família Contemporânea e as Implicações para a Saúde. In: TRAD, Leny A. Bomfim et.al. (Org.). Família Contemporânea e Saúde: significados, práticas e políticas públicas. Rio de Janeiro: Editora FIOCRUZ, 2010.

CARVALHO, Maria do Carmo Brant de. Famílias: conversas sobre políticas públicas e práticas. In: TRAD, Leny. A. Bomfim et.al. (Org.). Família Contemporânea e Saúde: significados, práticas e políticas públicas. Rio de Janeiro: Editora FIOCRUZ, 2010.

FERNANDES, Maria das Graças Melo; GARCIA, Loreley Gomes. O sentido da velhice para homens e mulheres idosos. In: Rev. Saúde e Sociedade. Vol. 19, n 4. p. 771-783, São Paulo: outubro-dezembro, 2010. Disponível em: http://dx.doi.org/10.1590/S0104-12902010000400005. Acesso em: 22 out. 2019.

FREITAS, Maria Célia. et al. O significado da velhice e da experiência de envelhecer para os idosos. In: Rev. Escola de Enfermagem da USP. Vol. 44, n 2, p. 407-412, São Paulo: junho de 2010. Disponível em: http://dx.doi.org/10.1590/S0880-62342010000200024. Acesso em: 24 out. 2019.

HEREDIA, Beatriz Maria Alásia. A morada da vida: Trabalho familiar de pequenos produtores no Nordeste do Brasil. Rio de Janeiro: Editora Paz e Terra, 1979.

MENEGAT, Alzira. Salete. Mulheres assentadas e suas lutas. In: ALMEIDA, Rosemeire Aparecida (Org.) A questão agrária em Mato Grosso do Sul: uma visão multidisciplinar. Campo Grande, MS: Ed. UFMS, 2008.

NERI, Anita Liberalesso. Qualidade de vida no adulto maduro: interpretações teóricas e evidências de pesquisa. In: Qualidade de vida e idade madura. São Paulo: Editora Papirus, 1993. 
PEREIRA, Marina Santos. Mulheres do campo: entre sonhos e realidades. 2015. (Mestrado em Sociologia). - FCH, Faculdade de Ciências Humanas, Universidade Federal da Grande Dourados, Dourados-MS. 2015.

REIS, Débora Martins Moreti. O envelhecimento em Dourados-MS: influência (s) de um centro de convivência de idosos na vida dos usuários. 2016. 139f. (Mestrado em Sociologia).FCH, Faculdade de Ciências Humanas, Universidade Federal da Grande Dourados, DouradosMS. 2016.

SCHNEIDER, Rodolfo Herberto; IRIGARAY, Tatiana Quarti. O envelhecimento na atualidade: aspectos cronológicos, biológicos, psicológicos e sociais. In: Rev. Estudos Psicológicos. Vol. 25, n 4, p. 586-593, Campinas: outubro-dezembro. 2008. Disponível em: http://dx.doi.org/10.1590/S0103-166X2008000400013. Acesso em: 16 out. 2019.

SKINNER, Burrhus Frederic; VAUGHAN, M. E. Viva bem a velhice: aprendendo a programar a sua vida. Tradução de Anita Liberalesso Neri. São Paulo: Editora Summus, 1985.

SANTOS, José Vicente Tavares dos. Colonos do vinho: Estudos sobre a subordinação do trabalho camponês ao capital. São Paulo: Editora Hucitec, 1978.

VERAS, Renato P.; RAMOS, Luiz Roberto; KALACHE, Alexandre. Crescimento da população idosa no Brasil: transformações e consequências na sociedade. In: Rev. Saúde Pública. Vol. 21 no. 3, p. 225-233, São Paulo: Junho, 1987. Disponível em: http://dx.doi.org/10.1590/50034-89101987000300007. Acesso em: 30 set. 2019. 